\title{
The effect of 2,4-dichlorophenoxyacetic acid on the production of oat (Avena sativa L.) doubled haploid lines through wide hybridization
}

\author{
Katarzyna Juzoń $^{\text {Corresp., } 1}{ }^{1}$, Marzena Warchoł ${ }^{1}$, Kinga Dziurka ${ }^{1}$, Ilona Czyczyło-Mysza ${ }^{1}$, Izabela Marcińska ${ }^{1}$, Edyta \\ Skrzypek $^{1}$ \\ ${ }^{1}$ Instytut Fizjologii Roślin im. Franciszka Górskiego PAN, Kraków, Polska \\ Corresponding Author: Katarzyna Juzoń \\ Email address: k.juzon@ifr-pan.edu.pl
}

Background. Development of new cultivars is one of the vital options for adapting agriculture to climate change, and the production of doubled haploid $(\mathrm{DH})$ plants can make a significant contribution to accelerating the breeding process. Oat is one of the cereals with particular health benefits, but it unfortunately still remains recalcitrant to haploidization. Our previous studies have clearly demonstrated that post-pollination with hormone treatment is a key step in haploid production through wide hybridization and indicated it as the most effective method for this species. Therefore, we subsequently addressed the problem of the influence of 2,4-dichlorophenoxyacetic acid (2,4-D) concentration on consecutive stages of $\mathrm{DH}$ production.

Methods. Twenty-nine genotypes were tested, 9,465 florets were pollinated with maize pollen 2 days after emasculation and then treated with 2,4-D at $50 \mathrm{mg} / \mathrm{L}$ and $100 \mathrm{mg} / \mathrm{L}$.

Results. The applied treatments did not reveal any differences in the number of obtained haploid embryos. However, almost twice as many haploid plants formed on MS medium after applying a higher auxin concentration and 20\% more successfully acclimatized. Moreover, $100 \mathrm{mg} / \mathrm{L}$ 2,4-D treatment resulted in twice as many $\mathrm{DH}$ lines that produced almost three times more seeds compared to $50 \mathrm{mg} / \mathrm{L}$ treatment. Nevertheless, the results have confirmed the existence of strong genotypic variation, which may significantly limit the development of an effective and economically feasible method that could be incorporated into breeding programs. 
1 The effect of 2,4-dichlorophenoxyacetic acid on the production of oat (Avena sativa $\mathbf{L}$.) 2 doubled haploid lines through wide hybridization

3 Katarzyna Juzoń ${ }^{1}$, Marzena Warchoł1, Kinga Dziurka ${ }^{1}$, Ilona Czyczyło-Mysza ${ }^{1}$, Izabela

4 Marcińska $^{1}$, Edyta Skrzypek ${ }^{1}$

5 'Department of Biotechnology, The Franciszek Górski Institute of Plant Physiology, Polish

6 Academy of Sciences, Krakow, Poland

8 Corresponding Author:

9 Katarzyna Juzoń ${ }^{1}$

10 Niezapominajek 21, Krakow 30-239, Poland

11 Email address: k.juzon@ifr-pan.edu.pl

\section{Abstract}

Background. Development of new cultivars is one of the vital options for adapting agriculture to climate change, and the production of doubled haploid (DH) plants can make a significant contribution to accelerating the breeding process. Oat is one of the cereals with particular health benefits, but it unfortunately still remains recalcitrant to haploidization. Our previous studies have clearly demonstrated that post-pollination with hormone treatment is a key step in haploid production through wide hybridization and indicated it as the most effective method for this species. Therefore, we subsequently addressed the problem of the influence of 2,4dichlorophenoxyacetic acid (2,4-D) concentration on consecutive stages of DH production.

Methods. Twenty-nine genotypes were tested, 9,465 florets were pollinated with maize pollen 2 days after emasculation and then treated with 2,4-D at $50 \mathrm{mg} / \mathrm{L}$ and $100 \mathrm{mg} / \mathrm{L}$.

Results. The applied treatments did not reveal any differences in the number of obtained haploid embryos. However, almost twice as many haploid plants formed on MS medium after applying a higher auxin concentration and 20\% more successfully acclimatized. Moreover, $100 \mathrm{mg} / \mathrm{L} \mathrm{2,4-D}$ treatment resulted in twice as many DH lines that produced almost three times more seeds compared to $50 \mathrm{mg} / \mathrm{L}$ treatment. Nevertheless, the results have confirmed the existence of strong genotypic variation, which may significantly limit the development of an effective and economically feasible method that could be incorporated into breeding programs.

\section{Introduction}


Oat (Avena sativa L.) constitutes the sixth most important cereal crop [Bekele et al. 2018, Hu et al. 2020] and remains a highly valued component of the human diet associated with dietary fiber such as $\beta$-glucan, functional protein, lipid and starch components, phytochemicals [Butt et al. 2008, Rasane et al. 2015] as well as phenolic compounds with antioxidant activity [Gray et al. 2002]. All these features make oat products highly recommended in gastrointestinal ailments and neoplastic conditions, classified as civilization diseases. However, oat production and its quality, like that of other cereal crops, strongly depends on climatic conditions. Currently, our population is facing the problem of long-term changes in the state of the climate [IPCC, 2014]. These alterations are believed to influence many aspects of our life, but their effects on agricultural production seem to be particularly severe. Despite the various obstacles to agricultural production, consumers will continue to demand tasty, convenient, healthy and safe food [Henry 2020]. One possible solution to counteract the negative impact of climate change is the development of new plant genotypes adapted to highly variable environmental conditions and pest infestations [Korres et al. 2016, Henry 2020].

Doubled haploid (DH) technology enables the instantaneous development of homozygous lines, which is a major breakthrough in accelerating cultivar development [Dunwell 2010], instead of 6-10 generations of inbreeding by selfing or sib-crossing [Prigge et al. 2012]. DHs are produced by androgenesis, gynogenesis, wide hybridization or interspecific crosses [Ferrie et al. 2014]. This technology for practical breeding is available in barley [Jacquard et al. 2006], wheat [Niu et al. 2014], and maize [Chaikam et al. 2019], in which thousands of DHs are produced annually using routine methods. However, in rye [Immonen and Tenhola-Roininen 2003], triticale [Immonen and Robinson 2000], potato [Rokka et al. 1996] and cabbage [Hansen 2003], DH technologies are less advanced. Unfortunately, despite countless health benefits, oat is considered as a species recalcitrant to haploidization [Sidhu et al. 2006, Marcińska et al. 2013, Skrzypek et al. 2016, Dziurka et al. 2019]. There are certain barriers that operates at pre and post fertilization phases which hinders the effectiveness of wide crossing of oat with maize. Firstly, oat endosperm usually fails to develop in seeds and the embryos must be rescued by transferred on culture medium to allow them to grow under optimum culture conditions. Therefore, selection of regeneration medium is the most critical step for the continued growth of the embryo. Moreover, all authors describe a very strong dependence of the development of haploid plants on the tested genotypes. So far, the efficiency of DH production in wheat reaches about $20 \%$ haploid per florets while in 
oat is less than one percent [Sidhu et al. 2006]. Oat haploids have been obtained by in vitro microspore/anther culture [Rines 1983, Sun et al. 1991, Kiviharju et al. 2005, Ponitka and Ślusarkiewicz-Jarzina 2009, Ferrie et al. 2014] as well as wide hybridizations [Rines et al. 1991, Rines 2003, Sidhu et al. 2006, Marcińska et al. 2013, Nowakowska et al. 2015], which is commonly indicated as the most effective method for this species [Rines 2003, Sidhu et al. 2006, Ishii et al. 2013, Marcińska et al. 2013, Nowakowska et al. 2015, Warchoł et al. 2016]. Therefore, wide crossing with maize (Zea mays L.) is most commonly applied in the commercial production of oat doubled haploid (DH) lines [Skrzypek et al. 2016], and no albino plants are produced among regenerants [Rines and Dahleen 1990].

Although numerous studies on the optimization of oat DH production have been published so far [Rines 2003, Sidhu et al. 2006, Marcińska et al. 2013, Nowakowska et al. 2015, Warchoł et al. 2016, Warchoł et al. 2019], the efficiency of this process is still disappointing, especially in the context of its use in breeding programs [Sidhu et al. 2006]. Many efforts have been made to increase its effectiveness and the work have focused, e.g. on (i) the species of the pollen donor [Rines 2003, Sidhu et al. 2006, Ishii et al. 2013, Nowakowska et al. 2015], (ii) applied media [Rines and Dahleen 1990, Kynast et al. 2001, Sidhu et al. 2006, Ishii et al. 2013, Nowakowska et al. 2015, Warchoł et al. 2016], (iii) type and concentration of supplemented carbohydrates [Rines et al. 1997, Kynast and Riera-Lizarazu 2011, Ishii et al. 2013, Marcińska et al. 2013, Niu et al. 2014, Nowakowska et al. 2015, Noga et al. 2016, Skrzypek et al. 2016, Warchoł et al. 2016] or (iv) light intensity during in vitro cultures [Skrzypek et al. 2016]. Wide crossing, involving fertilization with alien pollen, reduces embryo viability due to the absence of proper endosperm development. Therefore, the application of plant growth regulators (PGRs), which follows floret emasculation, is one of the crucial aspects in obtaining haploid embryos. 2,4-D is the auxin analogue the most widely used to control organ regeneration, callus induction or somatic embryogenesis induction [Wędzony et al. 2015]. Studies have shown that 2,4-D plays a central role in early and post-embryogenic plant development and mediates important steps during the early embryo patterning formation of zygotic embryogenesis [Nic-Can and Loyola-Vargas 2016]. Moreover, exogenously applied auxins change the level of endogenous auxins such as IAA and modify its metabolism inside the cell [Vondráková et al. 2016]. The increment in the endogenous IAA regulates the expression of a great number of transcription factors, several of them related to stress. Exogenous auxin seems to be required for the establishment of a normal embryonic 
95 symmetry at the globular and early transition stages embryos since both stages were affected 96 by manipulation of the auxin level or distribution. This dependence was confirmed by 97 immunohistological analysis of IAA in isolated zygotic and somatic embryos of cereals cultured 98 in vitro [Fischer and Neuhaus 1996, Przetakiewicz et al. 2003, Forestan et al. 2010]. These data 99 emphasize that the polar transport of auxin is essential for the formation of embryonic patterns and the distribution of this hormone is at all stages of embryo development, especially with the formation of bilateral symmetry in embryos. In DH line production, developed zygotes have a very low viability, and most of them abort during the initial stages of development. The application of auxins induces ovary enlargement and enhances the growth of the haploid embryos to a stage that enables their culture onto nutrient media [Laurie and Reymondie 1991] (12-16 days postpollination in wheat) [Mahato and Chaudhary 2019]). There is a general agreement on the need for applying synthetic auxins in DH line production as a means of recovering haploid embryos especially to applying them following pollination. The benefits of auxins is inducing rapid vacuolization and hydrolyzation of the embryo sac which, in turn, restrains fertilization [Matzk 1991]. Various auxin analogues (picloram; dicamba; 2,4-dichlorophenoxyacetic acid (2,4-D), gibberellic acid) (reviewed in Sidhu et al. [2006]) were tested for their ability to induce caryopsis and embryo formation, but no statistically significant differences between the applied substances or significant growth regulator $\times$ genotype interactions have been established so far [Warchoł et al. 2016]. Marcińska et al. [2013] reported that dicamba (3,6-dichloro-2-methoxybenzoic acid) treatment increased the size of the ovaries; however, 2,4-D application turned out to be more effective in converting embryos to haploid plants and obtaining DHs [Warchoł et al. 2016]. . Furthermore, haploid production efficiency is also affected by the concentration, time and hormone application method [Mahato and Chaudhary 2019].

Our previous long-term study have led to the development of a methodology for obtaining oat DH that assumed that pollination on the 2nd day after floret emasculation, and auxin treatment in the following 2 days were the most effective. In this study, we decided to investigate postpollination application of different 2,4-D concentrations in order to improve the efficiency of oat double haploid production by wide hybridization with maize. The purpose of this experiment was to demonstrate the influence of various auxin concentrations on each step of the process, i.e. haploid embryo formation, regeneration of haploid and DH plants as well as their fertility. The 
125 high complexity of this process demonstrates that there is still a need to explore the mechanisms

126 underlying DH production and all factors conditioning its effectiveness.

127

128

129

130

131

132

133

134

135

136

137

138

139

140

141

142

143

144

145

146

147

148

149

150

151

152

153

154

155

\section{Materials and Methods}

\section{Plant material}

Twenty-nine oat (Avena sativa L.) genotypes ( $\mathrm{F}_{1}$ progeny) were used in the study. Oat seeds were obtained from Danko Plant Breeding Ltd. (DC 11003, DC 11021, DC 11027, DC 11033, DC 11040, DC 11125, DC 11142, DC 11146, DC 11164, DC 11209, DC 11221 and DC 11244), Małopolska Plant Breeding Ltd. HBP Polanowice (POB 14/2013, POB 15/2013, POB 19/2013, POB 20/2013, POB 21/2013 and POB 38/2013) and Plant Breeding Strzelce Ltd., PBAI Group (STH 2.3602, STH 2.3618, STH 2.3619, STH 2.3621, STH 2.3626, STH 2.3628, STH 2.3644, STH 2.3646, STH 2.3659, STH 2.3668 and STH 2.9156). A mixture of three maize (Zea mays L. var. saccharata) genotypes was used as a pollen donor: MPC4, Dobosz and Wania according to Skrzypek et al. [2016]. Oat and maize plants were grown in the glasshouse under natural light conditions (photosynthetic active radiation (PAR) of $800 \mu \mathrm{mol} \mathrm{m}^{-2} \mathrm{~s}^{-1}$ and $16 \mathrm{~h} \mathrm{light} / 8 \mathrm{~h}$ dark) as well as optimal temperature for each species $\left(21 / 17^{\circ} \mathrm{C}\right.$ day/night and $21-28 / 17^{\circ} \mathrm{C}$ day/night for oat and maize respectively).

\section{Haploid plant production}

Two days after manually emasculation (Fig. 1A) florets were pollinated with a fresh maize pollen (collected at 15-min intervals) using a brush (Fig. 1B). The next day, one drop of $50 \mathrm{mg} / \mathrm{L}$ or 100 mg/L 2,4-D water solution was applied to each oat pistil (Fig. 1C). Three weeks later, enlarged ovaries (caryopses without endosperms) were surface-sterilized in $70 \% \mathrm{v} / \mathrm{v}$ ethanol (1 min), 2.5 \% calcium hypochlorite $(7 \mathrm{~min}), 0.1 \%$ mercuric chloride $(1 \mathrm{~min})$, washed three times with sterile water and then the embryos were isolated (Fig. 1D), transferred onto 190-2 medium (Wang and $\mathrm{Hu}, 1984)$ and cultured at $21 \pm 2{ }^{\circ} \mathrm{C}$, at the $16 \mathrm{~h}$ light at the intensity $60 \mu \mathrm{mol} \mathrm{m} \mathrm{m}^{-2} \mathrm{~s}^{-1}$. The developed haploid plants were grown on MS medium [Murashige and Skoog 1962] (Fig. 1E), then transferred to a moist perlite (PPUH Perlit Polska Ltd., Puńców, Poland) (Fig. 1F) and subsequently to soil (Fig. 1G) for acclimatization to ex vitro conditions. DH line plants were planted individually into $3 \mathrm{dm}^{3}$ pots with a diameter of $16 \mathrm{~cm}$ filled with soil composed of horticultural soil (Ekoziem, 
156 Jurków, Poland) and sand (2:1 v/v). Plants' acclimatization was performed in the glasshouse 157 condition described above. The seeds were obtained after 5-6 months. To show the efficiency of this method, the number of obtained haploid embryos per one hundred of pollinated florets was calculated.

\section{Chromosome doubling}

To double the number of chromosomes, when oat seedlings were at 4-5 leaf stage, colchicine treatment $(0.1 \%$ colchicine solution $)$ (Fig. 1H) was carried out according to [Warchoł et al. 2016] for $7.5 \mathrm{~h}$ at $25^{\circ} \mathrm{C}$ and $80-100 \mu \mathrm{mol} \mathrm{m} \mathrm{m}^{-2} \mathrm{~s}^{-1}$ light intensity. Next, the plant roots were rinsed with running water for $48 \mathrm{~h}$, and then planted singly into pots (Fig. 1I) for further growth and maturation under greenhouse conditions (temperature $21 / 17^{\circ} \mathrm{C}$ day/night in natural solar light). Plant ploidy level was measured before and one month after colchicine treatment (Fig. 2) using a MACS Quant flow cytometer (Miltenyi Biotec GmbH, Bergisch Gladbach, Germany), equipped with an aircooled laser (488 nm) and MACSQantify ${ }^{\mathrm{TM}}$ software. The young leaves (10-15 mg) were placed in a $60-\mathrm{mm}$ glass Petri dish with $1 \mathrm{ml}$ of the modified PBS buffer [Sambrook et al. 1989] and chopped with a razor blade in order to release nuclei and then filtered with a 30- $\mu$ m nylon mesh filter (Miltenyi Biotec GmbH, Bergisch Gladbach, Germany). The nuclei suspension was stained with $20 \mu \mathrm{l}$ of propidium iodide solution. As a control, oat plants derived from the seeds of known diploid DNA content were used.

All reagents used in the experiment were obtained from Sigma-Aldrich ${ }^{\circledR}$ (Sigma Aldrich, Darmstadt, Germany).

\section{Statistical analysis}

Data analysis was performed using two-way ANOVA implemented in the statistical package STATISTICA 13.0 (TIBCO Software Inc., Palo Alto, CA, USA). Differences between treatments were considered significant at $\mathrm{p} \leq 0.005$.

\section{Results}

The analysis of variance showed significant differences in the number of haploid plants obtained on MS medium relative to the tested genotype, auxin treatment $(50 \mathrm{mg} / \mathrm{L}$ or $100 \mathrm{mg} / \mathrm{L})$ and their 
186

187

188

189

190

191

192

193

194

195

196

197

198

interaction (Table 1). All examined factors were not significant with respect to the number of haploid embryos and DH lines produced.

\section{Effect of 2,4-D concentration on oat haploid embryo formation}

Nearly 9,500 oat florets from 29 genotypes were emasculated and pollinated with maize pollen, and then over 8,500 enlarged ovaries (some ovaries did not enlarge - Fig. 3A) were isolated (Tab. 2, Fig. 3B, C). In total, 619 haploid embryos were obtained (Fig. 3D, E) Their number between the tested genotypes and 2,4-D concentrations ranged from 1 to 31. Two genotypes, DC 11003 and DC 11221, developed the highest number of haploid embryos, while genotypes POB 38/2013 and STH 2.9156 the lowest, both after the application of $50 \mathrm{mg} / \mathrm{L}$ 2,4-D. Moreover, the haploidembryo-per-floret index reached the highest values (over 20\%) at the lower auxin concentration. Most of the tested genotypes showed values ranging from 5 to $10 \%-16$ genotypes (55\%) at 50 $\mathrm{mg} / \mathrm{L} 2,4-\mathrm{D}$, while 22 genotypes (76\%) at $100 \mathrm{mg} / \mathrm{L} 2,4-\mathrm{D}$.

\section{Effect of 2,4-D concentration on haploid plant development}

However, obtaining haploid embryos as the first step of this method did not guarantee the high final efficiency of obtaining haploid plants. . Despite the high number of isolated embryos (619), only $12.3 \%$ (76) germinated within 1-3 weeks of culturing (Fig. 3F, Tab. 2). Embryos from approximately a quarter of the studied genotypes (DC 11164, POB 14/2013, POB 15/2013, POB 20/2013, POB 38/2013, STH 2.3659 and STH 2.9156) did not germinate at all or died during development and, in consequence, failed to regenerate haploid plants, regardless of the applied auxin dose. Nevertheless, a clear difference between the two applied 2,4-D concentrations was noticed at this step: $50 \mathrm{mg} / \mathrm{L}$ 2,4-D resulted in an average of 27 haploid plants (8.5\%), while 49 haploids (16.3\%) were obtained at $100 \mathrm{mg} / \mathrm{L}$ 2,4-D (Fig. 3G). Although the highest number of haploid plants (5 haploids in genotype DC 11221) was recorded at the lower 2,4-D concentration, this treatment for most of the studied genotypes did not seem to be as favorable as the higher auxin dose. Embryos of 17 genotypes did not regenerate into plants at $50 \mathrm{mg} / \mathrm{L} \mathrm{2,4-D,} \mathrm{while} \mathrm{embryos} \mathrm{of}$ only 7 genotypes did not undergo further development after $100 \mathrm{mg} / \mathrm{L}$ 2,4-D treatment. Moreover, the higher auxin concentration allowed to obtain 4 haploid plants in 4 studied genotypes (DC 11003, DC 11142, DC 11221 and STH 2.3619), and 3 haploid plants in 5 genotypes (DC 11146, DC 11209, POB 21/2013, STH 2.3618 and STH 2.3644). 
216

217

218

219

220

221

222

223

224

225

226

227

228

229

230

231

232

233

234

235

236

237

238

239

240

241

242

243

244

245

246

All the haploid plants came from ten of the tested genotypes (DC 11033, DC 11040, DC 11146, DC 11209, DC 11244, POB 19/2013, POB 21/2013, STH 2.3619, STH 2.3628 and STH 2.3646) treated with the higher 2,4-D concentration (Fig. 4). In turn, among the remaining genotypes, $100 \mathrm{mg} / \mathrm{L} \mathrm{2,4-D}$ treatment resulted in not less than one third of haploid plants (as in genotype STH 2.3621), while for two genotypes (DC 11142 and STH 2.3644), haploids were obtained in almost $80 \%$. It is worth emphasizing that there was no genotype that produced haploids only after treatment with the lower auxin concentration.

The obtained haploid plants were subsequently transferred from Petri dishes to perlite and next to soil with sand (Fig. $3 \mathrm{H}$ ). The next critical step in $\mathrm{DH}$ production is the chromosome doubling procedure, including colchicine treatment. As not all plants survived it, some changes in the percent of the obtained DH plants in different 2,4-D concentrations were found compared to haploid plants ((Fig. 3I, Fig. 5). This procedure turned out to be an essential step for many of the studied genotypes, because, not all of the plants survived (Tab. 2). The highest plant mortality at 50 mg/L 2,4-D was observed in genotypes STH 2.3602, STH 2.3618, STH 2.3621, where at least half of the haploids did not survive colchicine treatment. In some genotypes (DC 11003, DC 11021, DC 11027, DC 11125, DC 11221, STH 2.3626, and STH 2.3644), all obtained haploid seedlings continued their growth (27\% of lines). On the other hand, $100 \mathrm{mg} / \mathrm{L} 2,4-\mathrm{D}$ treatment led to the death of the obtained plants in five genotypes (DC 11033, DC 11142, DC 11209, STH 2.3618 and STH 2.3628). However, higher auxin concentration contributed to $100 \%$ survival in as many as 17 genotypes i.e. about $58 \%$ of all lines. Attention should be drawn to genotype DC 11221, for which the highest number of haploid seedlings was obtained after $50 \mathrm{mg} / \mathrm{L} \mathrm{2,4-D}$ treatment, and where all of plants have successfully undergone colchicine treatment. Both applied auxin treatments led to the death of plants of genotypes DC 11164, POB 14/2013, POB 15/2013, POB 20/2013, POB 38/2013, STH 2.3659 and STH 2.9156.

\section{Effect of 2,4-D concentration on DH line development and seed production}

The number of obtained DH lines and seeds is presented in Table 3 and Fig. 6. The results of the experiment clearly showed the advantage of treatment with $100 \mathrm{mg} / \mathrm{L} \mathrm{2,4-D,} \mathrm{which} \mathrm{in} \mathrm{general}$ allowed to obtain twice as many DH plants (44 plants) compared to $50 \mathrm{mg} / \mathrm{L} \mathrm{2,4-D} \mathrm{(22} \mathrm{plants)}$ (Fig. 3J). This tendency was observed in 15 genotypes (DC 11003, DC 11033 (Fig. 3K), DC 11040, 
247 DC 11142, DC 11146, DC 11209, DC 11221, DC 11244, POB 19/2013 (Fig. 3L), POB 21/2013, 248 STH 2.3619 (Fig. 3M), STH 2.3628, STH 2.3644, STH 2.3646 and STH 2.3668), which accounted for 52\% of all tested genotypes. However, there were 3 genotypes (DC 11021, STH 2.3602 and STH 2.3621) where a lower 2,4-D concentration resulted in a higher number of DH lines; other 4 genotypes (DC 11027, DC 11125, STH 2.3618 and STH 2.3626) formed the same number of DH line, regardless of the applied auxin dose. The highest number of DH lines (4 DH lines) developed from genotypes DC 11003, DC 11142, DC 11221, and STH 2.3619 after 100 mg/L 2,4-D. Therefore, these results confirmed better efficiency of the higher auxin concentration and strong dependence of the method effectiveness on plant genotype. Although the number of DH lines obtained is undoubtedly the most important indicator of the effectiveness of the wide crossing method, plant fertility, and thus the ability to produce seeds is another very important factor. In total, DH lines produced 2,979 seeds of which $74 \%(2,207)$ were derived from plants treated with $100 \mathrm{mg} / \mathrm{L} 2,4-\mathrm{D}$. The most productive genotypes were: POB 21/2013, STH 2.3619 and STH 2.3646 (207, 194, and 169 seeds per DH line, respectively) after $100 \mathrm{mg} / \mathrm{L} 2,4-\mathrm{D}$ treatment, while $50 \mathrm{mg} / \mathrm{L} \mathrm{2,4-D}$ did not allow to obtain more than 100 seeds per $\mathrm{DH}$ line. In addition, the higher auxin concentration was associated with seed formation in $62 \%$ of genotypes, while a lower dose only in $28 \%$ of all tested genotypes.

\section{Discussion}

Various biotechnological techniques are used to obtain DH, which are indisputably a powerful tool in plant breeding. In oat (Avena sativa L.), wide hybridization through interspecific crosses is the most commonly applied DH system [Rines 2003, Sidhu et al. 2006, Ishii et al. 2013, Marcińska et al. 2013, Nowakowska et al. 2015, Warchoł et al. 2016], and wide crossing with maize (Zea mays L.) is most widely used in the commercial production of oat DH lines [Skrzypek et al. 2016]. Many factors have been shown to affect the efficiency of haploid/DH production, and unfortunately current methodology is still not cost-effective for a large-scale implementation.

As mentioned before, fertilization with alien pollen causes low embryo viability and zygote abortion during the initial stages of embryonic development. Post pollination application of PGRs, as a key step in chromosome elimination, can increase the recovery of haploid embryos to a state suitable for plant growth on nutrient media [Mahato and Chaudhary 2019]. Wędzony et al. [1998] found that dicamba and picloram were the most effective treatments for ovary growth and embryo 
278

production in triticale. Likewise, Knox et al. [2000] reported a similar effect of dicamba in durum wheat. However, 2,4-D has been indicated as the most effective in converting embryos to haploid plants and DH development in oat pollinated with maize [Marcińska et al. 2013, Wędzony et al. 2015, Warchoł et al. 2016]. Many years of research have prompted us to examine two concentrations of this synthetic auxin in the context of DH production efficiency, taking into account its influence on each step of this complex process. Chaudhary et al. [2015] and Mahato and Chaudhary [2015] showed in durum wheat $\times$ I. cylindrica that haploid induction was most responsive at a concentration of $250 \mathrm{mg} / \mathrm{L} 2,4-\mathrm{D}$. The application of $100 \mathrm{mg} / \mathrm{L} \mathrm{2,4-D}$ in oat haploid production led to the production of 1,5-2\% embryos per floret, depending on the studied genotype [Sidhu et al. 2006]. Marcińska et al. [2013] demonstrated that this parameter in most of the studied genotypes did not exceed $10 \%$, and $24 \%$ embryos per florets were obtained only in one genotype. In turn, Warchoł et al. [2016] tested 33 oat genotypes that did not produce more than 9 embryos per hundred emasculated florets. In our study, significantly higher values of this parameter were

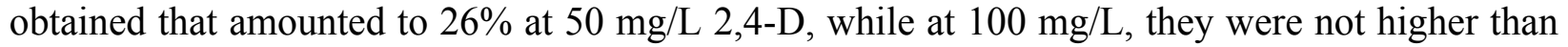
$11 \%$. However, most of the conducted studies did not consider the effect of auxin on further stages of DH production. Our findings have indicated that the influence of auxin should not be estimated/based on a single parameter. It was clearly shown that the haploid-embryo-per-floret ratio did not directly reflect the number of haploid/DH plants. Moreover, we demonstrated that the number of obtained haploids grown on MS medium was higher at $100 \mathrm{mg} / \mathrm{L}$ 2,4-D, because after this treatment embryos from over 70\% genotypes regenerated into plants, while at $50 \mathrm{mg} / \mathrm{L}$ only $40 \%$. In addition, according to [Rines 2003], this was a critical step since the germination rate of oat haploid embryos was typically low and did not exceed 20\%. Rines et al. [1997] showed that the application of a lower 2,4-D concentration $\left(10 \mathrm{mg} \mathrm{dm}^{-3}\right)$ resulted in obtaining caryopses more normal in shape and color than after a higher auxin concentration. On the other hand, the authors reported that using $100 \mathrm{mg} / \mathrm{L} \mathrm{2,4-D} \mathrm{contributed} \mathrm{to} \mathrm{enhanced} \mathrm{development} \mathrm{of} \mathrm{the} \mathrm{endosperm} \mathrm{and}$ whole embryos. After the application of $100 \mathrm{mg} / \mathrm{L} \mathrm{2,4-D,} \mathrm{Warchoł} \mathrm{et} \mathrm{al.} \mathrm{[2016]} \mathrm{obtained} \mathrm{in} \mathrm{total}$ 104 haploid plants on MS medium. What's more, according to Sourour et al [2011] the best effect of 2,4-D concentration in durum wheat $\times$ maize crosses was obtained with $100 \mathrm{mg} / \mathrm{L} \mathrm{2,4-D}$ in developed ovaries (65.90\%), embryos (23.62\%) and haploid plants (19.79\%). The same observation was reported by Garcia-Llamas et al. [2004] which showed that treatment with 100 $\mathrm{mg} / \mathrm{L}$ 2,4-D significantly increased the production of embryos and haploid plants and this 
concentration of 2,4-D was optimal for bread wheat $\times$ maize cross. Ushiyama et al. [2006] suggested that treatment with 2,4-D at $100 \mathrm{mg} / \mathrm{L}$ was also effective for haploid wheat production by Hordeum bulbosum method. 2,4-D in concentration 125, 150,175 mg/L was used by Sourour et al. [2011] and in $1000 \mathrm{mg} / \mathrm{L}$ by Suenaga [1994]. Caryopsis development in these studies was slightly improved at the higher 2,4-D concentration compared with $100 \mathrm{mg} / \mathrm{L}$ but the efficiency of embryo formation was four time decreased. Probably the higher concentrations of 2,4-D are toxic for generative tissues.

In our experiment, the tested genotypes produced in total 49 haploid plants after $100 \mathrm{mg} / \mathrm{L}$ treatment and 27 haploid plants after $50 \mathrm{mg} / \mathrm{L}$ 2,4-D. Moreover, the higher concentration of auxin also appeared to promote the acclimatization of haploids in soil as well as colchicine treatment resistance, which are both the next key steps in DH production. These observations were also confirmed by previous studies. Warchoł et al. [2016] showed that in total 44 DH lines were obtained from the tested genotypes at a higher auxin concentration, while in our study it was 44 DH lines at $100 \mathrm{mg} / \mathrm{L}$ and $22 \mathrm{DH}$ line at $50 \mathrm{mg} / \mathrm{L} \mathrm{2,4-D.} \mathrm{The} \mathrm{presented} \mathrm{results} \mathrm{indicated} \mathrm{an}$ additional significant feature of DH production - a high influence of the genotype, manifested in different responses of individual genotypes. This fact is an obstacle to the development of an effective method that could be commercially incorporated into breeding programs.

\section{Conclusions}

The efficiency of obtaining oat haploid and doubled haploid plants is strongly influenced by auxin treatment. The number of haploid embryos was comparable after both auxin treatments and did not guarantee their effective development into vigorous plants. Despite the genotypic variation, the higher 2,4-D concentration seemed to be more efficient in the context of obtaining haploid/DH plants as well as their vitality and fertility. Nevertheless, further research should focus on the manipulation of PGR treatments and embryo rescue conditions to optimize the efficiency of the oat $\mathrm{DH}$ production technique.

Acknowledgments The authors thank Danko Plant Breeding Ltd., Małopolska Plant Breeding Ltd. HBP Polanowice and Plant Breeding Strzelce Ltd., PBAI Group for oat seeds used this study.

\section{References}


339Bekele, W.A., Wight, C.P., Chao, S., Howarth, C.J., Tinker, N.A. (2018). Haplotype-based 340 genotyping-by-sequencing in oat genome research. Plant Biotechnol J 16:1452-1463. 341 https://doi.org/10.1111/pbi.12888

342Butt, M.S., Tahir-Nadeem, M., Khan, M.K.I., Shabir, R., Butt, M.S. (2008). Oat: Unique among the 343 cereals. Eur J Nutr 47:68-79. https://doi.org/10.1007/s00394-008-0698-7

344Chaikam, V., Molenaar, W., Melchinger, A.E., Boddupalli, P.M. (2019). Doubled haploid technology 345 for line development in maize: technical advances and prospects. Theor Appl Genet 132:3227346 3243. https://doi.org/10.1007/s00122-019-03433-x

347Chaudhary, H.K., Mahato, A., Kaila, V., Rather, S.A., Tayeng, T. (2015). Dihaploid Induction in 348 tetraploid durum wheat (Triticum durum 1.) using pollen of Imperata cylindrica. Czech J Genet 349 Plant Breed 51:142-147. https://doi.org/10.17221/218/2014-cjgpb

350Dunwell, J.M. (2010). Haploids in flowering plants: Origins and exploitation. Plant Biotechnol J 351 8:377-424. https://doi.org/10.1111/j.1467-7652.2009.00498.x

352Dziurka, K., Dziurka, M., Warchoł, M., Czyczyło-Mysza, I., Marcińska, I., Noga, A., Kapłoniak, K., 353 Skrzypek, E. (2019). Endogenous phytohormone profile during oat (Avena sativa L.) haploid 354 embryo development. In Vitro Cell Dev Biol Plant 55:221-229. https://doi.org/10.1007/s11627355 019-09967-5

356Ferrie, A.M.R., Irmen, K.I., Beattie, A.D., Rossnagel, B.G. (2014). Isolated microspore culture of oat 357 (Avena sativa L.) for the production of doubled haploids: effect of pre-culture and post-culture 358 conditions. Plant Cell Tiss Org 116:89-96. https://doi.org/10.1007/s11240-013-0385-0

359Fischer, Ch., Neuhaus, G. (1996). Influence of auxin on the establishment of bilateral symmetry in 360 monocots. The Plant Journal 9(5): 659-669 https://doi.org/10.1046/j.1365313X.1996.9050659.x

361Forestan, C., Meda, S., and Varotto, S. (2010). ZmPIN1-mediated auxin transport is related to cellular 362 differentiation during maize embryogenesis and endosperm development. Plant Physiol. 363 152:1373-1390. https://doi: 10.1104/pp.109.150193

364García-Llamas, C., Martín, A., Ballesteros, J. (2004). Differences among auxin treatments on haploid 365 production in durum wheat $\times$ maize crosses. Plant Cell Rep. 23:46-49

366Gray, D.A., Clarke, M.J., Baux, C., Bunting, J.P., Salter, A.M. (2002). Antioxidant activity of oat 367 extracts added to human LDL particles and in free radical trapping assays. J Cereal Sci 36:209368 218. https://doi.org/10.1006/jcrs.2001.0456

369Hansen, M. (2003). Protocol for microspore culture in Brassica. In M. M, K.J. K, B.P. F and I. S (eds) 370 Doubled Haploid Production in Crop Plants. Springer, Dordrecht, pp. 217-222.

371Henry, R.J. (2020). Innovations in plant genetics adapting agriculture to climate change. Curr Opin 372 Plant Biol 56:168-173. https://doi.org/10.1016/j.pbi.2019.11.004

373Hu, H., Gutierrez-Gonzalez, J.J., Liu, X., Yeats, T.H., Garvin, D.F., Hoekenga, O.A., Sorrells, M.E., 374 Gore, M.A., Jannink, J.L. (2020). Heritable temporal gene expression patterns correlate with 375 metabolomic seed content in developing hexaploid oat seed. Plant Biotechnol J 18:1211-1222. 376 https://doi.org/10.1111/pbi.13286

377Immonen, S., Robinson, J. (2000). Stress treatments and ficoll for improving green plant regeneration 378 in triticale anther culture. Plant Sci 150:77-84. https://doi.org/10.1016/s0168-9452(99)00169-7 379Immonen, S., Tenhola-Roininen, T. (2003). Protocol for rye anther culture. In Maluszynski M, Kasha 380 KJ, Forster BP and Szarejko I (eds) Doubled haploid production in crop plants. Springer, The 381 Netherlands, pp. 141-149.

382IPCC, (2014). Climate change 2014: Impacts, adaptation, and vulnerability. Part A: Global and 383 sectoral aspects. In Field CB, Barros VR, Dokken DJ, Mach KJ, Mastrandrea MD, Bilir TE, 384 Chatterjee M, Ebi KL, Estrada YO, Genova RC, Girma B, Kissel ES, Levy AN, MacCracken S, 
385 Mastrandrea PR and White LL (eds) Contribution of Working Group II to the Fifth Assessment 386 Report of the Intergovernmental Panel on Climate Change. Cambridge University Press, 387 Cambridge, United Kingdom and New York, NY, USA, pp. 1132p.

388Ishii, T., Tanaka, H., Eltayeb, A.E., Tsujimoto, H. (2013). Wide hybridization between oat and pearl 389 millet belonging to different subfamilies of Poaceae. Plant Reprod 26:25-32. 390 https://doi.org/10.1007/s00497-012-0205-4

391Jacquard, C., Asakaviciute, R., Hamalian, A.M., Sangwan, R.S., Devaux, P., Clement, C. (2006). 392 Barley anther culture: effects of annual cycle and spike position on microspore embryogenesis and 393 albinism. Plant Cell Rep 25:375-381. https://doi.org/10.1007/s00299-005-0070-9

394Kiviharju, E., Moisander, S., Laurila, J. (2005). Improved green plant regeneration rates from oat 395 anther culture and the agronomic performance of some DH lines. Plant Cell Tiss Org 81:1-9. 396 https://doi.org/10.1007/s11240-004-1560-0

397Knox, R.E., Clarke, J.M., DePauw, R.M. (2000). Dicamba and growth condition effects on doubled 398 haploid production in durum wheat crossed with maize. Plant Breed 119:289-298. 399 https://doi.org/10.1046/j.1439-0523.2000.00498.x

400Korres, N.E., Norsworthy, J.K., Tehranchian, P., Gitsopoulos, T.K., Loka, D.A., Oosterhuis, D.M., 401 Gealy, D.R., Moss, S.R., Burgos, N.R., Miller, M.R., Palhano, M. (2016). Cultivars to face climate 402 change effects on crops and weeds: A review. Agron Sustain Dev 403 36https://doi.org/10.1007/s13593-016-0350-5

404Kruglova, N.N., Seldimirova, O.A., Zinatullina, A.E. (2020). Structural Features and Hormonal 405 Regulation of the Zygotic Embryogenesis in Cereals. Biol Bull Rev 10: 115-126 406 https://doi.org/10.1134/S2079086420020048

407Kynast, R.G., Riera-Lizarazu, O. (2011). Development and use of oat-maize chromosome additions 408 and radiation hybrids. In Birchler JS (ed) Plant Chromosome Engineering. Springer, New York, 409 pp. 259-284.

410Kynast, R.G., Riera-Lizarazu, O., Vales, M.I., Okagaki, R.J., Maquieira, S.B., Chen, G., Ananiev, 411 E.V., Odland, W.E., Russell, C.D., Stec, A.O., Livingston, S.M., Zaia, H.A., Rines, H.W., Phillips, 412 R.L. (2001). A complete set of maize individual chromosome additions to the oat genome. Plant 413 Physiol 125:1216-1227. https://doi.org/10.1104/pp.125.3.1216

414Laurie, DA, Reymondie, S. (1991). High frequencies of fertilization and haploid seedling production 415 in crosses between commercial hexaploid wheat varieties and maize. Plant Breed 106:182-189 416 https://doi.org/10.1111/j.1439-0523.1991.tb00499.x

417Mahato, A., Chaudhary, H.K. (2015). Relative efficiency of maize and Imperata cylindrica for haploid 418 induction in Triticum durum following chromosome elimination-mediated approach of doubled 419 haploid breeding. Plant Breed 134:379-383. https://doi.org/10.1111/pbr.12288

420Mahato, A., Chaudhary, H.K. (2019). Auxin induced haploid induction in wide crosses of durum 421 wheat. Cereal Res Commun 47:552-565. https://doi.org/10.1556/0806.47.2019.31

422Marcińska, I., Nowakowska, A., Skrzypek, E., Czyczyło-Mysza, I. (2013). Production of double 423 haploids in oat (Avena sativa L.) by pollination with maize (Zea mays L.). Cent Eur J Biol 8:306424 313. https://doi.org/10.2478/s11535-013-0132-2

425Matzk, F. (1991). A novel approach to differentiated embryos in the absence of endosperm. Sex Plant 426 Reprod 4: 8-94 https://doi.org/10.1007/BF00196493

427Murashige, T., Skoog, F. (1962). A revised medium for rapid growth and bioassays with tobacco 428 tissue cultures. Physiol Plant 15:473-497. https://doi.org/10.1111/j.1399-3054.1962.tb08052.x 
429Nic-Can, G.I., Loyola-Vargas, V.M. (2016). The Role of the Auxins During Somatic Embryogenesis. 430 In: Loyola-Vargas V., Ochoa-Alejo N. (eds) Somatic Embryogenesis: Fundamental Aspects and 431 Applications. (Cham: Springer), pp 171-181 https://doi.org/10.1007/978-3-319-33705-0 10 432Niu, Z., Jiang, A., Abu Hammad, W., Oladzadabbasabadi, A., Xu, S.S., Mergoum, M., Elias, E.M. 433 (2014). Review of doubled haploid production in durum and common wheat through wheatxmaize 434 hybridization. Plant Breed 133:313-320. https://doi.org/10.1111/pbr.12162

435Noga, A., Skrzypek, E., Warchoł, M., Czyczyło-Mysza, I., Dziurka, K., Marcińska, I., Juzoń, K., 436 Warzecha, T., Sutkowska, A., Nita, Z., Werwińska, K. (2016). Conversion of oat (Avena sativa 437 L.) haploid embryos into plants in relation to embryo developmental stage and regeneration media. 438 In Vitro Cell Dev Biol Plant 52:590-597. https://doi.org/10.1007/s11627-016-9788-z

439Nowakowska, A., Skrzypek, E., Marcińska, I., Czyczyło-Mysza, I., Dziurka, K., Juzoń, K., Cyganek, 440 K., Warchoł, M. (2015). Application of chosen factors in the wide crossing method for the 441 production of oat doubled haploids. Open Life Sci 10:112-118. https://doi.org/10.1515/biol-20154420014

443Ponitka, A., Ślusarkiewicz-Jarzina, A. (2009). Regeneration of oat androgenic plants in relation to 444 induction media and culture condition of embryo-like structures. Acta Soc Bot Pol 78:209-213. 445 https://doi.org/10.5586/asbp.2009.026

446Prigge, V., Xu, X., Li, L., Babu, R., Chen, S., Atlin, G.N., Melchinger, A.E. (2012). New insights 447 into the genetics of in vivo induction of maternal haploids, the backbone of doubled haploid 448 technology in maize. Genetics 190:781-U804. https://doi.org/10.1534/genetics.111.133066

449Przetakiewicz, A., Orczyk, W., Nadolska-Orczyk, A. (2003). The effect of auxin on plant 450 regeneration of wheat, barley and triticale. Plant Cell Tissue Organ Cult. 73: 245-256. 451 https://doi.org/10.1023/A:1023030511800

452Rasane, P., Jha, A., Sabikhi, L., Kumar, A., Unnikrishnan, V.S. (2015). Nutritional advantages of oats 453 and opportunities for its processing as value added foods: A review. J Food Sci Tech Mys 52:662454 675. https://doi.org/10.1007/s13197-013-1072-1

455Rines HW (1983) Oat anther culture: genotype effects on callus initiation and the production of a 456 haploid $\quad$ plant. Crop $\quad$ Sci $23: 268-272$. 457 https://doi.org/10.2135/cropsci1983.0011183X002300020022x

458Rines, H. (2003). Oat haploids from wide hybridization. In Maluszynski M, Kasha KJ, Forster BP 459 and Szarejko I (eds) Doubled Haploid Production in Crop Plants. Springer Science+Business 460 Media, LLC, Dordrecht, pp. 155-159.

461Rines, H., Davis, D., Busch, R. (1991). Use of male steriles in producing haploid wheat and oat plants 462 by wide cross hybridization. Am Soc Agron Abstracts 114

463Rines, H.W., Dahleen, L.S. (1990). Haploid oat plants produced by application of maize pollen to 464 emasculated oat $\quad$ florets. $\quad$ Crop $\quad$ Sci $\quad 30: 1073-1078$. 465 https://doi.org/10.2135/cropsci1990.0011183X003000050023x

466Rines, H.W., Riera-Lizarazu, O., Nunez, V.M., Davis, D.W., Phillips, R.L. (1997). Oat haploids from 467 anther culture and from wide hybridizations. In Mohan Jain S, Sopory SK and Veilleux RE (eds) 468 In vitro haploid production in higher plants. Springer, Dordrecht, pp. 205-221.

469Rokka, V.M., Pietila, L., Pehu, E. (1996). Enhanced production of dihaploid lines via anther culture 470 of tetraploid potato (Solanum tuberosum L ssp tuberosum) clones. Am J Potato Res 73:1-12. 471 https://doi.org/10.1007/bf02849299

472Sambrook, J., Fritsch, E.F., Maniatis, T. (1989). Molecular cloning: a laboratory manual. Cold Spring 473 Harbor Laboratory Press; Cold Spring Harbor, New York. 
474Sidhu, P.K., Howes, N.K., Aung, T., Zwer, P.K., Davies, P.A. (2006). Factors affecting oat haploid 475 production following oat $\mathrm{x}$ maize hybridization. Plant Breed 125:243-247. 476 https://doi.org/10.1111/j.1439-0523.2006.01206.x

477Skrzypek, E., Warchoł, M., Czyczyło-Mysza, I., Marcińska, I., Nowakowska, A., Dziurka, K., Juzoń, 478 K., Noga, A. (2016). The effect of light intensity on the production of oat (Avena sativa L.) doubled 479 haploids through oat $\mathrm{x}$ maize crosses. Cereal Res Commun 44:490-500.

480 https://doi.org/10.1556/0806.44.2016.007

481Sourour, A., Olfa, S.A., Hajer, S.A. (2011). Effect of 2,4-dichlorophenoxyacetic acid and nitrate 482 silver on the efficiency of haploid production in durum wheat $\times$ maize crosses. Int. J. Plant Breed., 483 5:101-105

484Suenaga, K. (1994). Doubled haploid system using the intergeneric crosses between wheat 485 (Triticumaestivum) and maize (Zea mays). Bull. Natl. Inst. Agrobiol. Resour., 9:83-139

486Sun, J-s., Lu, T-G., Sōndahl, M. (1991). Anther culture of naked oat and the establishment of its 487 haploid suspension cell. J Integr Plant Biol 33

488Ushiyama, T., Kuwabara, T.Yoshida, T. (2006) Effect of 2,4- Dichlorophenoxyacetic acid on the 489 efficiency of wheat haploid production by the Hordeum bulbosum method, Plant Prod. Sci., 9(3): 490 206-211 Vondráková, Z., Krajňáková, J., Fischerová, L., Vágner, M., Eliášová, K. (2016). 491 Physiology and role of plant growth regulators in somatic embryogenesis. In: Park Y-S, Bonga J, 492 Moon H-K (eds) Vegetative propagation of forest trees. National Institute of Forest Science 493 (NIFoS), Seoul, pp 123-169.

494Wang, X., Hu, H. (1984). The effect of potato II medium for triticale anther culture. Plant Sci Lett 495 36:237-239. https://doi.org/10.1016/0304-4211(84)90175-5

496Warchoł, M., Czyczyło-Mysza, I., Marcińska, I., Dziurka, K., Nog,a A., Kapłoniak, K., Pilipowicz, 497 M., Skrzypek, E. (2019). Factors inducing regeneration response in oat (Avena sativa L.) anther 498 culture. In Vitro Cell Dev Biol Plant 55:595-604. https://doi.org/10.1007/s11627-019-09987-1

499Warchoł, M., Czyczyło-Mysza, I., Marcińska, I., Dziurka, K., Noga, A., Skrzypek, E. (2018). The 500 effect of genotype, media composition, $\mathrm{pH}$ and sugar concentrations on oat (Avena sativa L.) 501 doubled haploid production through oat $\mathrm{x}$ maize crosses. Acta Physiol Plant 502 40https://doi.org/10.1007/s11738-018-2669-9

503Warchoł, M., Skrzypek, E., Nowakowska, A., Marcińska, I., Czyczyło-Mysza, I., Dziurka, K., Juzoń, 504 K., Cyganek, K. (2016). The effect of auxin and genotype on the production of Avena sativa L. 505 doubled haploid lines. Plant Growth Regul 78:155-165. https://doi.org/10.1007/s10725-015-00825066

507Wędzony, M., Marcińska, I., Ponitka, A., Ślusarkiewicz-Jarzina, A., Woźna, J. (1998). Production of 508 doubled haploids in Triticale (X Triticosecale Wittm) by means of crosses with maize (Zea mays 509 L) using picloram and dicamba. Plant Breed 117:211-215. https://doi.org/10.1111/j.1439510 0523.1998.tb01928.x

511Wędzony, M., Żur, I., Krzewska, M., Dubas, E., Szechyńska-Hebda, M., Wąsek, I. (2015). Doubled 512 haploids in triticale. In Eudes F (ed) Triticale. Springer, Cham, pp. 111-128.

513

514

515

516

517 


\section{Table $\mathbf{1}$ (on next page)}

Two way analysis of variance in oat doubled haploid production using the wide hybridization method, showing the significance of genotype, auxin treatment and their interaction with measured trait.

SS - sum of squares, $d f$ - degrees of freedom, MS - mean squares, ns - not significant; ${ }^{*} p \leq$ 0.005 


\begin{tabular}{llrcrrr}
\hline Trait & $\begin{array}{l}\text { Source of } \\
\text { variance }\end{array}$ & \multicolumn{1}{c}{ SS } & $\boldsymbol{d f}$ & MS & $\boldsymbol{F}$ & $\boldsymbol{p}$ \\
\hline \multirow{2}{*}{$\begin{array}{l}\text { Number of haploid } \\
\text { embryos/ }\end{array}$} & Genotype & 4823.98 & $28(\mathrm{~g}-1)$ & 172.285 & 58.618 & $2 \times 10^{-3} \mathrm{~ns}$ \\
100 emasculated florets & Auxin & 18.02 & $1(\mathrm{a}-1)$ & 18.023 & 218.000 & $1 \times 10^{-3} \mathrm{~ns}$ \\
& Genotype $\times$ Auxin & 2645.98 & $28(\mathrm{a}-1) \times(\mathrm{g}-1)$ & 94.499 & 49.123 & $4 \times 10^{-3} \mathrm{~ns}$ \\
& Residual error & $1 \times 10^{-3}$ & $116(\mathrm{a} \times \mathrm{g}-1) \times(\mathrm{n}-1)$ & 0.000 & & \\
\hline \multirow{2}{*}{$\begin{array}{l}\text { Number of haploid plants } \\
\text { on MS medium/100 }\end{array}$} & Genotype & 184.29 & $33(\mathrm{~g}-1)$ & 5.585 & 63.293 & $1 \times 10^{-5 *}$ \\
emasculated florets & Genotype $\times$ Auxin & 85.18 & $33(\mathrm{a}-1) \times(\mathrm{g}-1)$ & 2.581 & 29.253 & $4 \times 10^{-5 *}$ \\
& Residual error & 12.00 & $136(\mathrm{a} \times \mathrm{g}-1) \times(\mathrm{n}-1)$ & 0.088 & & \\
\hline \multirow{3}{*}{$\begin{array}{l}\text { Number of DH lines/100 } \\
\text { emasculated florets }\end{array}$} & Genotype & 176.69 & $28(\mathrm{~g}-1)$ & 6.310 & 61.567 & $1 \times 10^{-2} \mathrm{~ns}$ \\
& Guxin & 25.03 & $1(\mathrm{a}-1)$ & 25.034 & 325.790 & $2 \times 10^{-3} \mathrm{~ns}$ \\
& Renotype $\times$ Auxin & 82.97 & $28(\mathrm{a}-1) \times(\mathrm{g}-1)$ & 2.963 & 28.240 & $3 \times 10^{-3} \mathrm{~ns}$ \\
\hline
\end{tabular}




\section{Table 2 (on next page)}

The influence of 2,4-D concentration ( $50 \mathrm{mg} / \mathrm{L}$ or $100 \mathrm{mg} / \mathrm{L}$ ) on the efficiency of haploid embryo and DH plant production using the wide crossing method. 


\begin{tabular}{|c|c|c|c|c|c|c|c|c|c|c|c|c|c|c|}
\hline \multirow[t]{2}{*}{ Genotype } & \multicolumn{2}{|c|}{$\begin{array}{l}\text { Pollinated } \\
\text { florets }\end{array}$} & \multicolumn{2}{|c|}{$\begin{array}{l}\text { Isolated } \\
\text { ovaries }\end{array}$} & \multicolumn{2}{|c|}{$\begin{array}{l}\text { Haploid } \\
\text { embryos }\end{array}$} & \multicolumn{4}{|c|}{$\begin{array}{l}\text { Haploid embryos/florets } \\
{[\% \pm \text { SE }]}\end{array}$} & \multicolumn{2}{|c|}{$\begin{array}{l}\text { Haploid plants } \\
\text { on MS medium }\end{array}$} & \multicolumn{2}{|c|}{$\begin{array}{l}\text { Plants after } \\
\text { colchicine } \\
\text { treatment }\end{array}$} \\
\hline & $50 \mathrm{mg}$ & $100 \mathrm{mg}$ & $50 \mathrm{mg}$ & $100 \mathrm{mg}$ & $50 \mathrm{mg}$ & $100 \mathrm{mg}$ & & $50 \mathrm{mg}$ & & $100 \mathrm{mg}$ & $50 \mathrm{mg}$ & $100 \mathrm{mg}$ & $50 \mathrm{mg}$ & $100 \mathrm{mg}$ \\
\hline DC 11003 & 139 & 139 & 131 & 135 & 31 & 15 & 25.8 & \pm 3.06 & 11.0 & \pm 0.83 & 2 & 4 & 2 & 4 \\
\hline DC 11021 & 197 & 124 & 193 & 121 & 15 & 12 & 13.9 & \pm 3.30 & 9.4 & \pm 0.50 & 3 & 2 & 3 & 2 \\
\hline DC 11027 & 302 & 133 & 268 & 137 & 20 & 10 & 8.6 & \pm 1.46 & 7.5 & \pm 0.73 & 1 & 1 & 1 & 1 \\
\hline DC 11033 & 124 & 279 & 117 & 263 & 3 & 22 & 4.7 & \pm 0.00 & 7.8 & \pm 0.34 & 0 & 2 & 0 & 1 \\
\hline DC 11040 & 99 & 232 & 92 & 206 & 5 & 12 & 4.5 & \pm 1.42 & 5.2 & \pm 0.31 & 0 & 1 & 0 & 1 \\
\hline DC 11125 & 311 & 175 & 288 & 167 & 19 & 14 & 7.0 & \pm 2.00 & 8.2 & \pm 0.70 & 1 & 1 & 1 & 1 \\
\hline DC 11142 & 164 & 209 & 160 & 203 & 7 & 11 & 4.4 & \pm 1.00 & 5.4 & \pm 0.37 & 1 & 4 & 1 & 3 \\
\hline DC 11146 & 94 & 188 & 88 & 181 & 10 & 12 & 9.7 & \pm 7.27 & 6.2 & \pm 0.48 & 0 & 3 & 0 & 3 \\
\hline DC 11164 & 229 & 190 & 224 & 181 & 5 & 4 & 5.8 & \pm 2.92 & 2.1 & \pm 0.49 & 0 & 0 & 0 & 0 \\
\hline DC 11209 & 181 & 151 & 158 & 134 & 3 & 6 & 4.4 & \pm 1.68 & 4.0 & \pm 0.38 & 0 & 3 & 0 & 2 \\
\hline DC 11221 & 292 & 124 & 259 & 112 & 31 & 7 & 9.7 & \pm 1.83 & 5.9 & \pm 0.49 & 5 & 4 & 5 & 4 \\
\hline DC 11244 & 170 & 144 & 157 & 135 & 8 & 9 & 6.8 & \pm 1.80 & 6.3 & \pm 0.50 & 0 & 1 & 0 & 1 \\
\hline POB $14 / 2013$ & 79 & 175 & 70 & 164 & 2 & 13 & 2.5 & \pm 0.16 & 7.6 & \pm 3.54 & 0 & 0 & 0 & 0 \\
\hline POB $15 / 2013$ & 79 & 178 & 43 & 168 & 5 & 12 & 6.3 & \pm 0.00 & 6.7 & \pm 0.42 & 0 & 0 & 0 & 0 \\
\hline POB 19/2013 & 92 & 170 & 87 & 160 & 6 & 10 & 6.2 & \pm 2.80 & 6.1 & \pm 0.33 & 0 & 1 & 0 & 1 \\
\hline POB 20/2013 & 101 & 89 & 94 & 82 & 3 & 6 & 4.5 & \pm 0.80 & 6.4 & \pm 0.37 & 0 & 0 & 0 & 0 \\
\hline POB 21/2013 & 60 & 150 & 58 & 140 & 8 & 10 & 13.3 & \pm 0.00 & 6.5 & \pm 0.32 & 0 & 3 & 0 & 3 \\
\hline POB 38/2013 & 13 & 73 & 9 & 65 & 1 & 2 & 7.7 & \pm 0.00 & 3.2 & \pm 0.72 & 0 & 0 & 0 & 0 \\
\hline STH 2.3602 & 253 & 175 & 242 & 170 & 18 & 13 & 9.2 & \pm 1.70 & 7.4 & \pm 0.80 & 3 & 2 & 1 & 2 \\
\hline STH 2.3618 & 240 & 153 & 218 & 140 & 12 & 10 & 6.2 & \pm 1.40 & 6.3 & \pm 0.53 & 4 & 3 & 2 & 1 \\
\hline STH 2.3619 & 82 & 206 & 79 & 196 & 14 & 19 & 20.2 & \pm 2.14 & 9.1 & \pm 0.43 & 0 & 4 & 0 & 4 \\
\hline STH 2.3621 & 182 & 214 & 180 & 207 & 21 & 13 & 11.5 & \pm 2.40 & 6.1 & \pm 0.36 & 2 & 1 & 1 & 1 \\
\hline STH 2.3626 & 284 & 153 & 234 & 146 & 12 & 10 & 9.1 & \pm 1.66 & 6.5 & \pm 0.46 & 3 & 2 & 3 & 2 \\
\hline STH 2.3628 & 293 & 155 & 269 & 149 & 20 & 14 & 8.3 & \pm 2.10 & 9.1 & \pm 0.70 & 0 & 1 & 0 & 0 \\
\hline
\end{tabular}




\begin{tabular}{lrrrrrrrrrrrr} 
STH 2.3644 & 176 & 112 & 165 & 109 & 7 & 6 & $5.8 \pm 0.80$ & $5.7 \pm 0.43$ & 1 & 3 & 1 & 3 \\
STH 2.3646 & 243 & 80 & 215 & 75 & 7 & 6 & $4.8 \pm 0.97$ & $7.1 \pm 1.17$ & 0 & 1 & 0 & 1 \\
STH 2.3659 & 164 & 134 & 161 & 124 & 8 & 4 & $5.2 \pm 0.98$ & $2.7 \pm 0.35$ & 0 & 0 & 0 & 0 \\
STH 2.3668 & 215 & 128 & 200 & 123 & 17 & 14 & $8.8 \pm 1.40$ & $10.9 \pm 0.77$ & 1 & 2 & 1 & 2 \\
STH 2.9156 & 36 & 139 & 36 & 122 & 1 & 5 & $2.7 \pm 0.00$ & $3.4 \pm 0.30$ & 0 & 0 & 0 & 0 \\
Total/average* & $\mathbf{4 8 9 4}$ & $\mathbf{4 5 7 1}$ & $\mathbf{4 4 9 5}$ & $\mathbf{4 3 1 7}$ & $\mathbf{3 1 9}$ & $\mathbf{3 0 0}$ & $* \mathbf{8 . 2} \pm \mathbf{1 . 6 2}$ & $* \mathbf{6 . 5} \pm \mathbf{0 . 6 3}$ & $\mathbf{2 7}$ & $\mathbf{4 9}$ & $\mathbf{2 2}$ & $\mathbf{4 3}$ \\
\hline
\end{tabular}




\section{Table 3 (on next page)}

Effect of 2,4-D concentration $(50 \mathrm{mg} / \mathrm{L}$ or $100 \mathrm{mg} / \mathrm{L}$ ) on the development of doubled haploid plants (DH lines) and seed production (Number of seeds, Seeds/DH line). 


\begin{tabular}{|c|c|c|c|c|c|c|}
\hline \multirow{2}{*}{ Genotype } & \multicolumn{2}{|c|}{ DH lines } & \multicolumn{2}{|c|}{ Number of seeds } & \multicolumn{2}{|c|}{ Seeds/DH lines } \\
\hline & $50 \mathrm{mg} / \mathrm{L}$ & $100 \mathrm{mg} / \mathrm{L}$ & $50 \mathrm{mg} / \mathrm{L}$ & $100 \mathrm{mg} / \mathrm{L}$ & $50 \mathrm{mg} / \mathrm{L}$ & $100 \mathrm{mg} / \mathrm{L}$ \\
\hline DC 11003 & 2 & 4 & 0 & 120 & 0 & 30 \\
\hline DC 11021 & 3 & 1 & 100 & 18 & 33 & 18 \\
\hline DC 11027 & 1 & 1 & 36 & 40 & 36 & 40 \\
\hline DC 11033 & 0 & 2 & 0 & 5 & 0 & 3 \\
\hline DC 11040 & 0 & 1 & 0 & 6 & 0 & 6 \\
\hline DC 11125 & 1 & 1 & 6 & 35 & 6 & 35 \\
\hline DC 11142 & 1 & 4 & 0 & 24 & 0 & 6 \\
\hline DC 11146 & 0 & 2 & 0 & 91 & 0 & 46 \\
\hline DC 11164 & 0 & 0 & 0 & 0 & 0 & 0 \\
\hline DC 11209 & 0 & 3 & 0 & 68 & 0 & 23 \\
\hline DC 11221 & 3 & 4 & 87 & 85 & 29 & 21 \\
\hline DC 11244 & 0 & 1 & 0 & 91 & 0 & 91 \\
\hline РОB 14/2013 & 0 & 0 & 0 & 0 & 0 & 0 \\
\hline РОB 15/2013 & 0 & 0 & 0 & 0 & 0 & 0 \\
\hline РОВ 19/2013 & 0 & 1 & 0 & 0 & 0 & 0 \\
\hline POB 20/2013 & 0 & 0 & 0 & 0 & 0 & 0 \\
\hline POB 21/2013 & 0 & 1 & 0 & 207 & 0 & 207 \\
\hline POB 38/2013 & 0 & 0 & 0 & 0 & 0 & 0 \\
\hline STH 2.3602 & 3 & 1 & 114 & 0 & 38 & 0 \\
\hline STH 2.3618 & 3 & 3 & 278 & 54 & 93 & 18 \\
\hline STH 2.3619 & 0 & 4 & 0 & 774 & 0 & 194 \\
\hline STH 2.3621 & 2 & 1 & 82 & 0 & 41 & 0 \\
\hline STH 2.3626 & 2 & 2 & 69 & 291 & 35 & 146 \\
\hline STH 2.3628 & 0 & 1 & 0 & 0 & 0 & 0 \\
\hline STH 2.3644 & 0 & 3 & 0 & 121 & 0 & 40 \\
\hline STH 2.3646 & 0 & 1 & 0 & 169 & 0 & 169 \\
\hline STH 2.3659 & 0 & 0 & 0 & 0 & 0 & 0 \\
\hline STH 2.3668 & 1 & 2 & 0 & 8 & 0 & 4 \\
\hline STH 2.9156 & 0 & 0 & 0 & 0 & 0 & 0 \\
\hline Total & 22 & 44 & 772 & 2207 & 311 & 1097 \\
\hline
\end{tabular}

2 


\section{Figure 1}

Diagram of the production of oat doubled haploid lines through the wide crossing method.

(A) floret emasculation, (B) floret pollination with maize pollen, (C) 2,4-D application to the pistil, (D) embryo isolation, (E) in vitro culture of embryos on MS medium and their conversion into haploid plants, (F) haploid plants grown in perlite, $(\mathbf{G})$ haploid plant acclimatization in soil, (H) chromosomes doubling by colchicine treatment, (I) DH plant grown in soil until maturity.

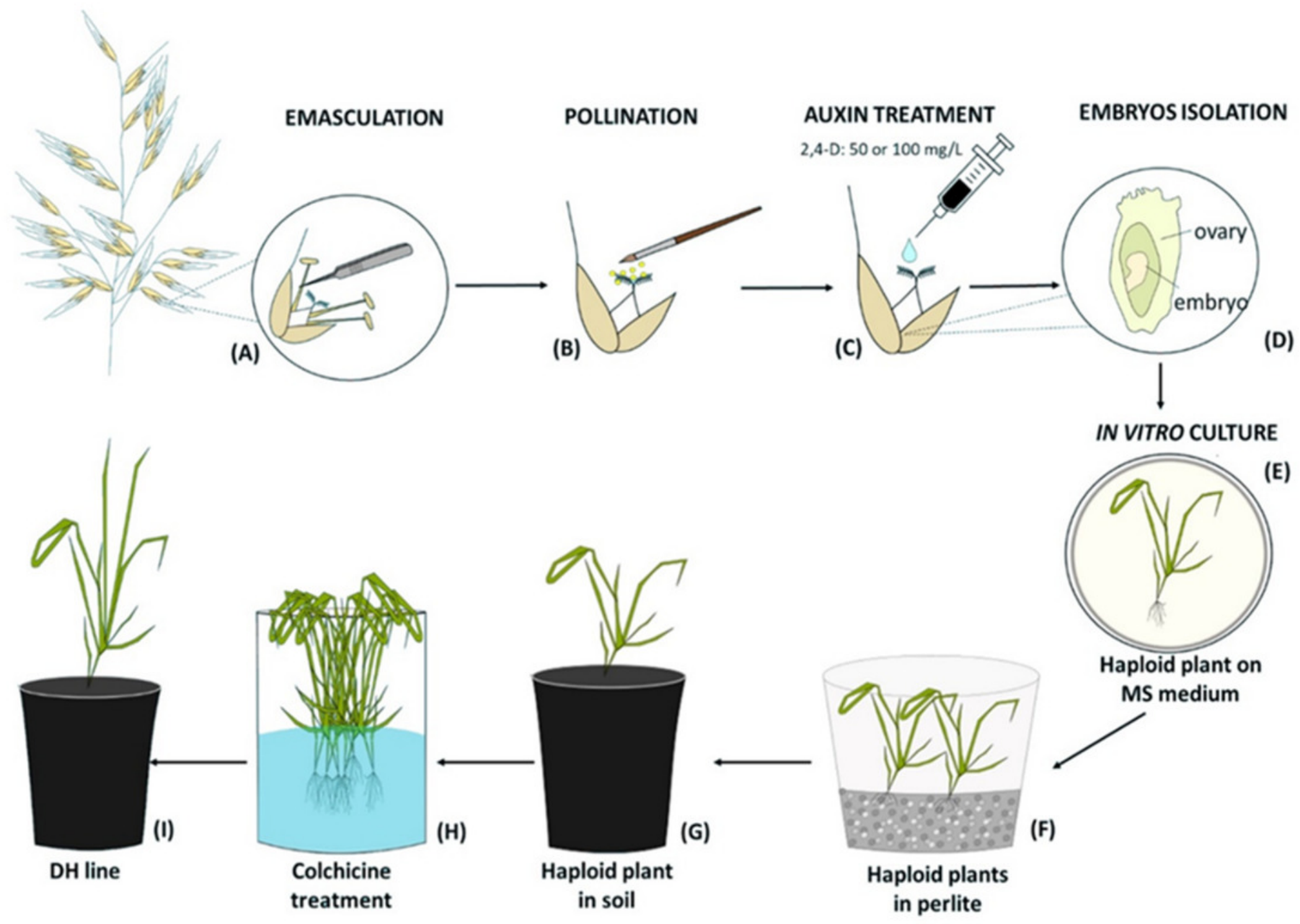


Figure 2

Flow cytometry histograms of oat plants: (A) control $2 n-c v$. Bingo, (B) haploid in DC11142 before colchicine treatment, and (C) doubled haploid 2n - DC11142 after colchicine treatment.
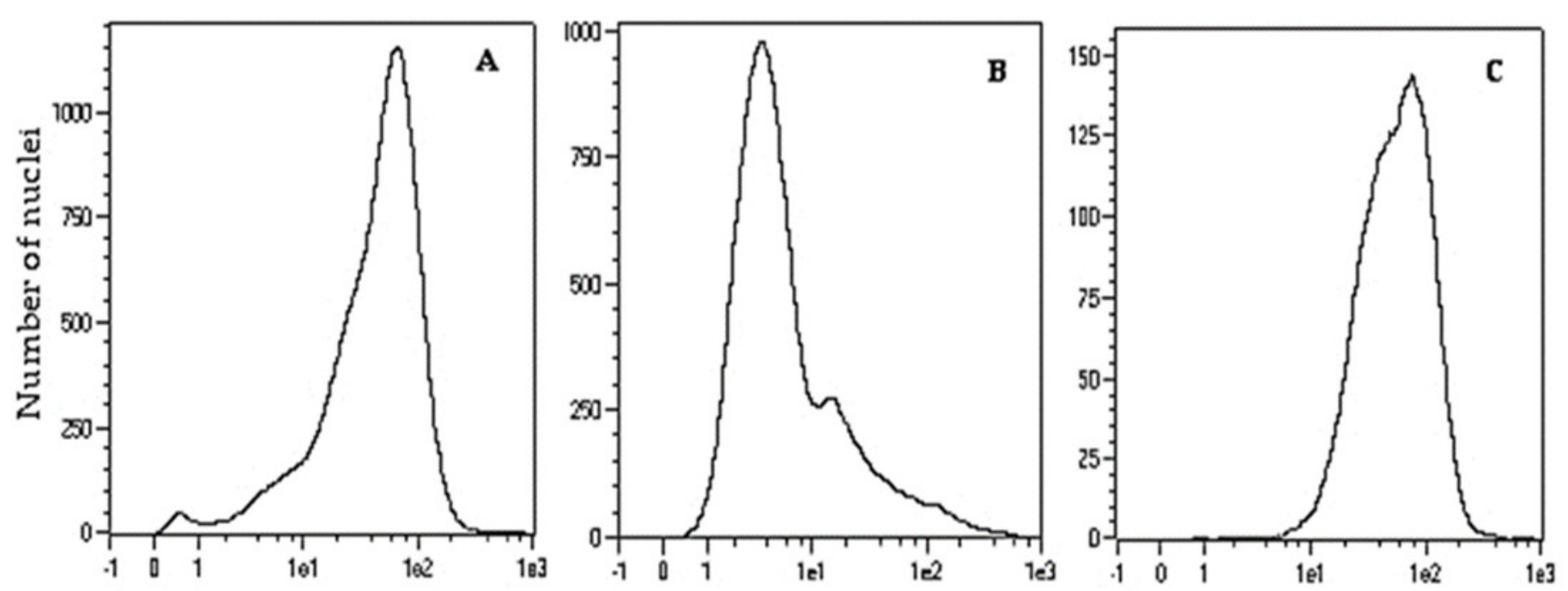

Relative DNA content 


\section{Figure 3}

Oat doubled haploids production by wide crossing with maize.

(A) non-enlarged ovary, (B) enlarged ovary after $50 \mathrm{mg} / \mathrm{L}$ 2,4-D treatment, (C) enlarged ovary after $100 \mathrm{mg} / \mathrm{L}$ 2,4-D treatment, (D) haploid embryo inside ovary, (E) haploid embryo isolated from ovary, (F) germinated haploid embryo, (G) developed haploid plant, (H) haploid plants acclimated to the natural conditions before colchicine treatment, (I) plants after colchicine treatment, (J) maturating DH plants in the greenhouse, (K) panicles of DH lines DC 11003, (L) panicles of DH lines POB 19/2013, (M) panicles of DH lines STH 2.3619. 

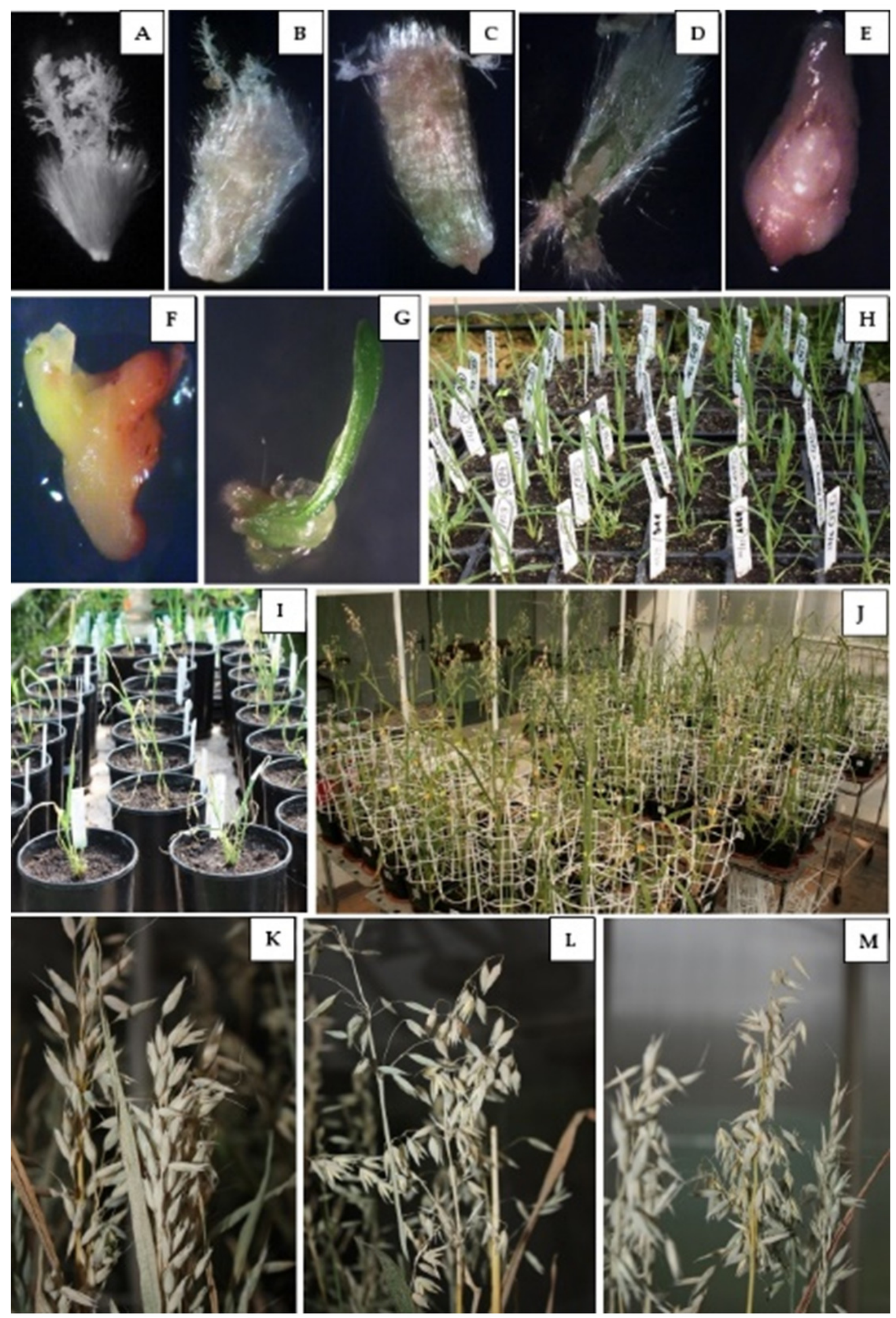
Figure 4

Percent of haploid plants [\%] grown on MS medium obtained after application of two tested 2,4-D concentrations: $50 \mathrm{mg} / \mathrm{L}$ - blue bars or $100 \mathrm{mg} / \mathrm{L}$ - grey bars.

Bars shows what percentage of the obtained plants came from a given treatment $(50 \mathrm{mg} / \mathrm{L} \mathrm{or}$ $100 \mathrm{mg} / \mathrm{L} 2,4-\mathrm{D})$.

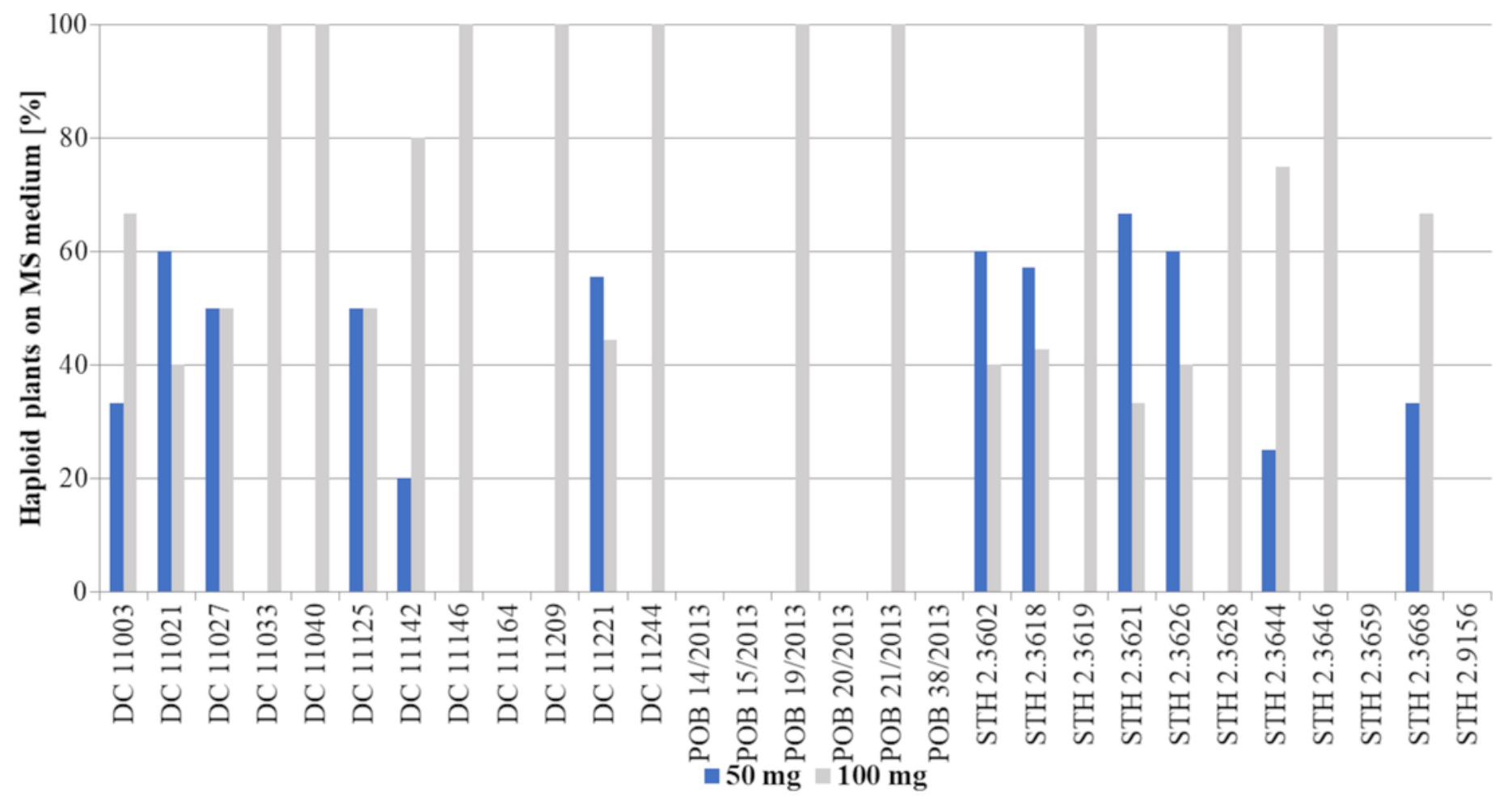


Figure 5

Percent of plants [\%] after colchicine treatment depending on two tested 2,4-D concentrations: $50 \mathrm{mg} / \mathrm{L}$ - blue bars or $100 \mathrm{mg} / \mathrm{L}$ - grey bars.

Bars shows what percentage of the obtained plants came from a given treatment $(50 \mathrm{mg} / \mathrm{L}$ or $100 \mathrm{mg} / \mathrm{L} 2,4-\mathrm{D})$.

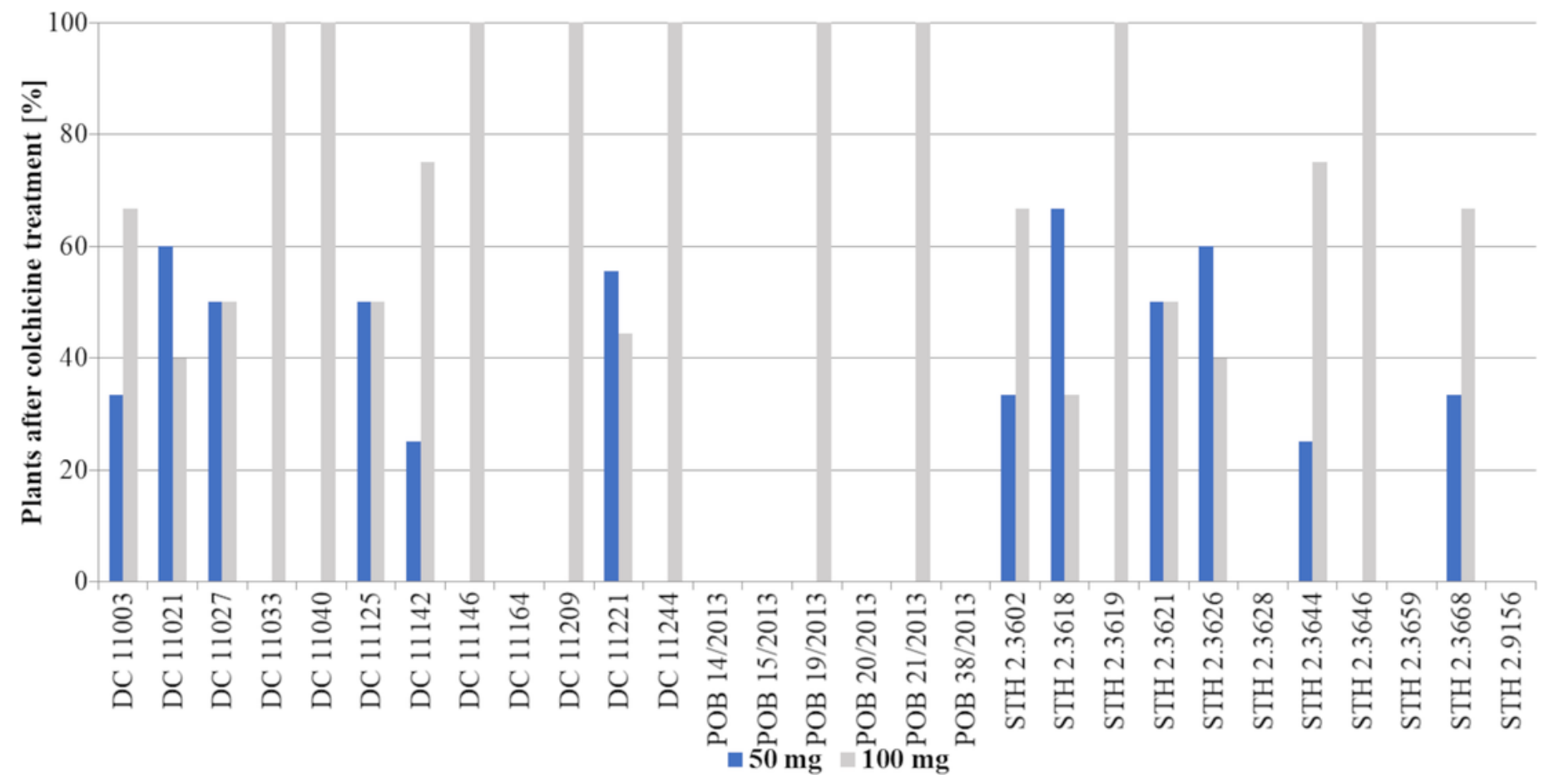


Figure 6

Percent of DH lines [\%] obtained after application of two tested 2,4-D concentrations: 50 $\mathrm{mg} / \mathrm{L}$ - blue bars or $100 \mathrm{mg} / \mathrm{L}$ - grey bars.

Bars shows what percentage of the obtained plants came from a given treatment $(50 \mathrm{mg} / \mathrm{L} \mathrm{or}$ $100 \mathrm{mg} / \mathrm{L} 2,4-\mathrm{D})$.

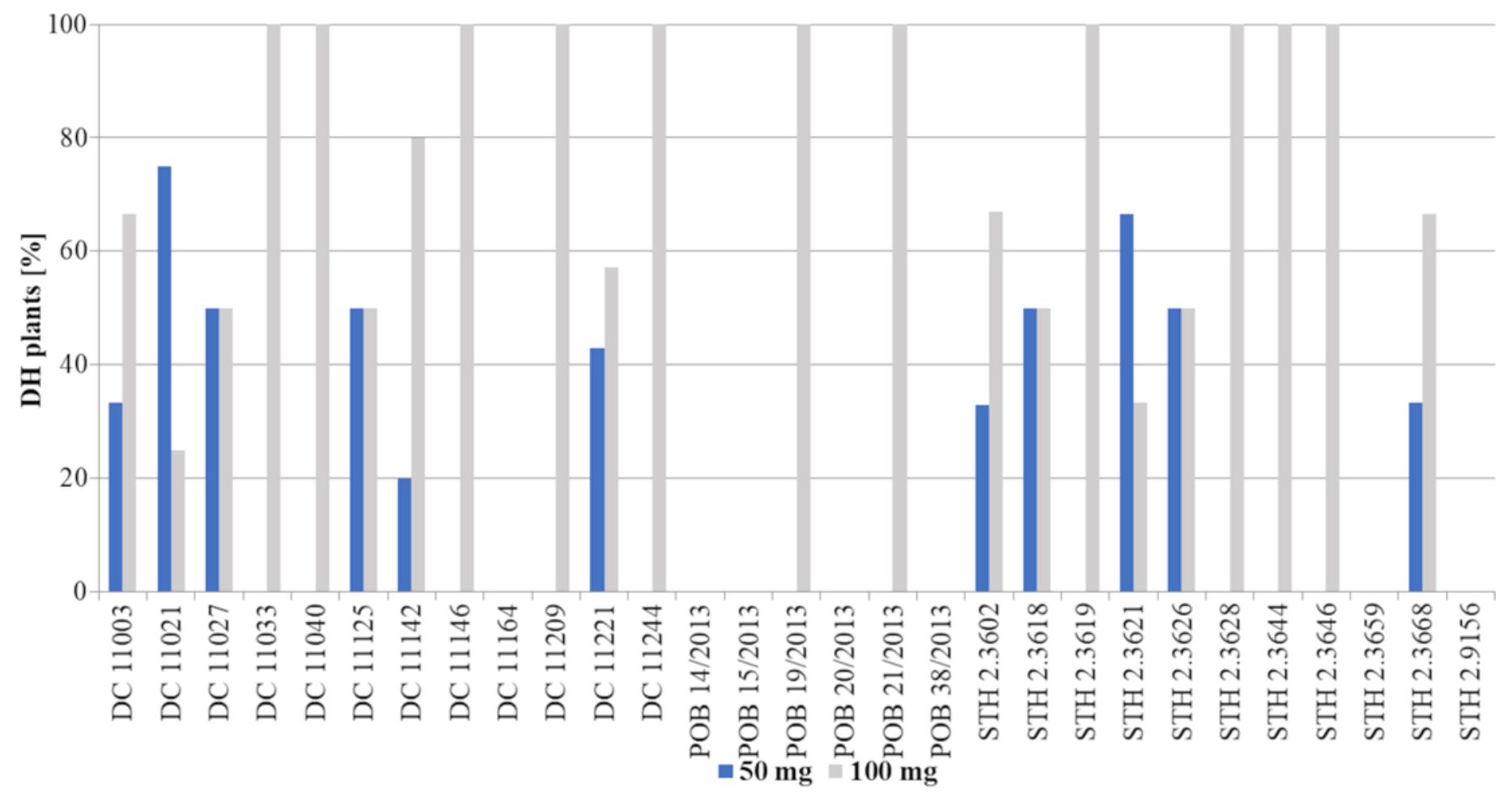

